\title{
Activating BRAF Mutation
}

National Cancer Institute

\section{Source}

National Cancer Institute. Activating BRAF Mutation. NCI Thesaurus. Code C139795.

A change in the nucleotide sequence of the BRAF gene that that results in constitutive activation of both serine/threonine-protein kinase B-raf and its downstream signaling pathways. 